\title{
RECYCLING OF USED LUBRICATING ENGINE OIL BY A SOLVENT EXTRACTION PROCESS
}

\section{DINESH KELOTH KAITHARI*, PRADEEP KUMAR KRISHNAN \& ABDULLAH AL-RIYAMI}

Department of Mechanical and Industrial Engineering, College of Engineering, National University of Science and Technology (NUST), Muscat, Sultanate of Oman

\begin{abstract}
Automotive lubricating oil is a high pollutant that needs significant management and accountability from the community and government. These oils in soil or water currents, such as sewage, can harm the environment. Groundwater and soil may become polluted by this. Lubricant costs are lowered by recycling these pollutants into useful products. This is a creative way of treating waste and will have a huge effect on the environment as well. This will decrease air/water contamination and fresh raw materials as well and greenhouse gas emissions will be minimized by recycling. Refining therefore restores the substantial and chemical properties of lubricating oil, which is capable of reverting to the original and intended usage of the oil used for the production of mixed essential oils in lubricants, minimizing the use of virgin oils. To return to its original intended use, recycling reproduces the physical and chemical properties of lubricants. This article explores the refining of lubricating oil using the solvent process and vacuum distillation, by oil recycling technology. Using three types of solvents: 1-propanol, n-butanol, and ethanol, the laboratory experiment was based on a complete global design. The purpose of this document was to recycle engine oil and recover valuable products. Impurities were isolated by filtration and separation, then to recover useful products by solvent extraction. We measured the specific gravity, density, viscosity, flash point, fire point, pour point, sulphate ash content, total base quantity, colour, residue of carbon, water content and compared the original oil. The kinematic and dynamic viscosity of recovered oil was found to be greater by different separation methods at lower temperatures.
\end{abstract}

KEYWORDS: Recycling, Solvent Extraction \& Simple distillation

Received: Jan 06 2020; Accepted: Jan 26, 2021; Published: Feb 02, 2021; Paper Id.: IJMPERDFEB202114

\section{INTRODUCTION}

Managing oil use is one of any single individual's key social obligations. Waste systems differ with time and place, where industrial improvement and growth are closely linked to waste materials. Where certain discarded parts are commercially useful and can be used again. By minimizing friction and degradation between interacting materials, lubricants are sticky liquids used to facilitate the relative movement of solid objects. The safety of internal combustion engines in automobiles and control machinery is the largest application (Boyde, 2002). Ninety percent of the essential oil is included in the lubricating oil model. Oil fractures are most commonly called mineral oils, and fewer than ten percent are added. The chemical degradation of these additives during use has resulted in halogenated hydrocarbons being accumulated in the crude. As well as other polycyclic compounds produced and deposited in the gasoline, polycyclic aromatic hydrocarbons (PAHs) are generated (Wong and Wang, 2001), along with the metal wear and tear of the lubricated engine (Chung et al., 2007). The consistency of these compounds decreases, resulting in a change in physical and chemical properties and hence worsening (Liu et al, 2005). When released into the atmosphere, these chemicals are particularly poisonous, having adverse effects on marine 
organisms and human beings (Kanokkantaponga et al., 2009). The improper handling of the lubricating oil used to pollute the atmosphere to a considerable degree when at least two hundred and fifty thousand volumes of water may be polluted by each volume of this article (Liu et al, 2005). Therefore, sound control of this dangerous material is necessary to make it a profitable commodity by drastically minimizing the amount of disposal that is inappropriately disposed of (Dang,2006). The refinement of the lubricating oil used would also eliminate the environmental risks faced and preserve crude oil supplies (Durani et al., 2010). There are several techniques available for replenishing used lubricants, including chemical treatment (Rahman et al., 2008; Hani and Al-Wedyan, 2012), distillation and thin evaporation physical treatment (Shakirullah et al., 2006), and solvent extraction (Katiyar and Husain, 2010). The recovery of solvent extraction engine oil offers a way to recycle the oil used through quick distillation pr Oil in developing countries is the biggest energy supply and still it is a small natural resource. Consequently, the renewal of restricted natural resources is an economic and environmentally sustainable process.

\section{MATERIALS AND METHODOLOGY}

2.1 Materials. For the experimental study of this test, the used oil sample is collected; the sample is drained directly from one of the three engine generators at the car service centre (garage). It is understood that fresh oil was used in the engine for 10000 kilometers before being removed in compliance with the repair manual of the generator. The experiment consists of examining and handling the motor oil used (used oils collected by car). In order to establish an effective refining process, laboratory experiments may aid. The oil used for solvents is combined by filtration, distillation and contrast of the initial oil and the extracted oil to restore usable products, separators and products. Any email, a subsection. The instruments and chemicals used in this study are shown in Table 2.1.

Table 2.1: List of Equipment and Chemicals Used

\begin{tabular}{|c|c|}
\hline Items & Purpose \\
\hline Oil used (plastic bottle) & Sample collection \\
\hline Semi - automatic Cleveland flash point tester & Measure flash point \\
\hline Filter paper (Whatman) & Used for fuel filters \\
\hline Magnetic stirrer with hot plate & $\begin{array}{l}\text { Is a device in a laboratory that uses a rotating } \\
\text { magnetic field to cause a bar }\end{array}$ \\
\hline Electronic weighing scale & For weighing materials \\
\hline Saybolt Viscometer & Measuring viscosity \\
\hline Spectrophotometer & $\begin{array}{l}\text { Used to extent how much a chemical substance } \\
\text { takes light by measuring the intensity of light as a } \\
\text { beam of light passes through sample solution }\end{array}$ \\
\hline ISCO syringe pumps & Used for fuel filters \\
\hline Simple distillation & $\begin{array}{l}\text { Used to activate or change the state (or phase) of the } \\
\text { material to enhance desired properties }\end{array}$ \\
\hline Funnel & $\begin{array}{l}\text { Used to connect liquid or fine-grained substances } \\
\text { into containers with a small opening }\end{array}$ \\
\hline Glass Beakers & Sample and product handling \\
\hline Thermometer & Measuring temperature \\
\hline Picnometer & Measuring density \\
\hline Mixer & Mixing the samples with solvent \\
\hline 1-Propanol, n-Butanol, Ethanol & Solvent for extraction \\
\hline
\end{tabular}




\begin{tabular}{|l|l|}
\hline Gloves, Mouth mask, Eyeglass & Safety \\
\hline Cleaning materials (kerosene, detergents, water, sponge) & Cleaning the equipment and working area \\
\hline Aluminium foil & Covering the sample beakers \\
\hline Stationary materials (masking tape, marker) & Labelling sample \\
\hline
\end{tabular}

2.2 Methods. Whatman filter paper ( $5 \mathrm{Nos}$ ) has been taken and $40 \mathrm{ml}$ of the engine oil used has been filtered. The method of filtration was carried out in the laboratory. Because of the presence of ash and other impurities, some of the samples took more time for filtration. The ratio of pure oil extracted is greater than ash and impurities as the filtration time is increased. The recycling Process Flowchart as seen in Figure 2.1.

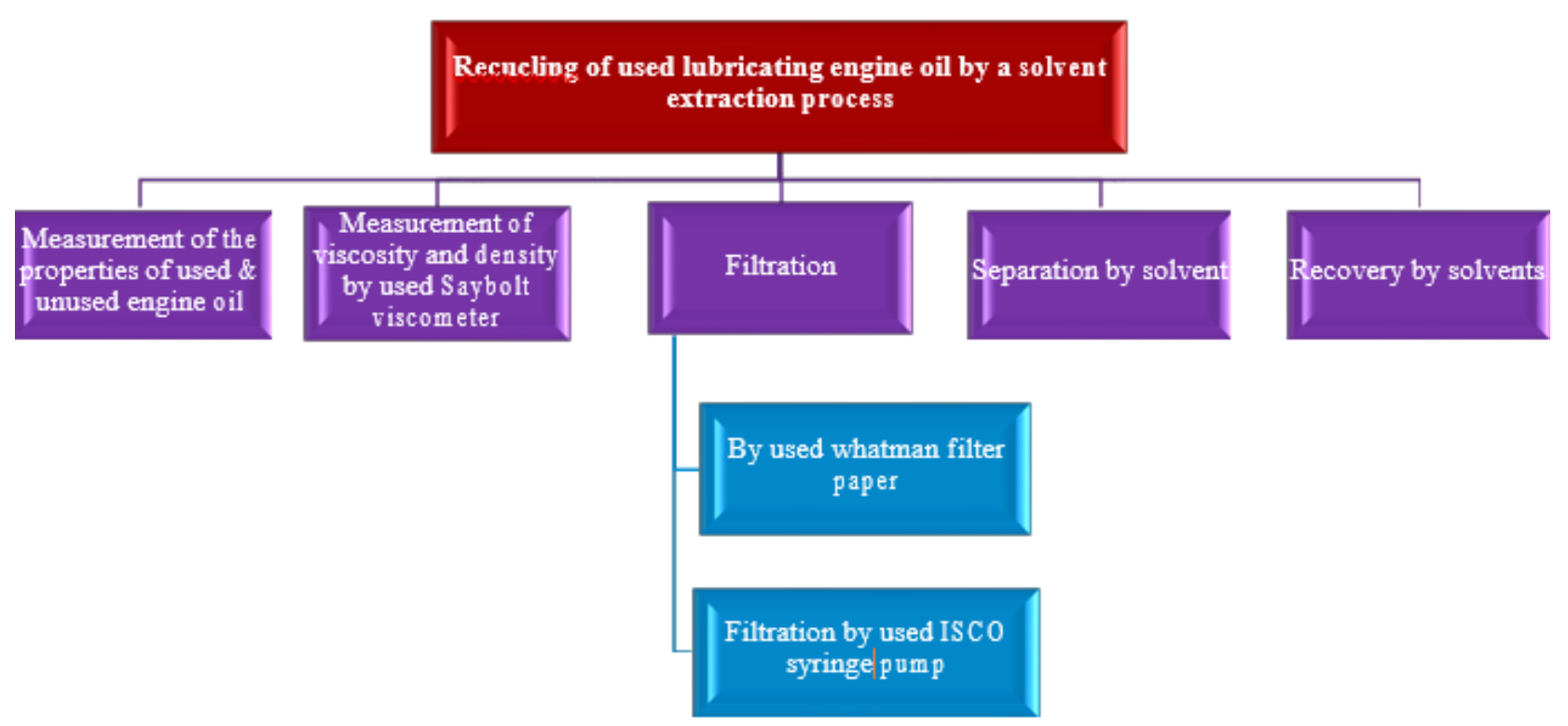

Figure 2.1: Flowchart of Recycling Process.

The second technique used the ISCO syringe pump system consisting of pumps, a vertical tube comprising $500 \mathrm{ml}$ of water that assists in the recovery process of used engine oil. The length of the process was three hours. With less impurities, the amount of pure oil extracted is higher. Separation of used engine oil with solvents such as n-Butanol, 1Propanol and Ethanol was the third process. In the beaker, $100 \mathrm{ml}$ of used fuel oil and $100 \mathrm{ml}$ of ethanol were obtained. This was then exposed to hot-plate magnetic stirring. The mixture was kept in the isolation funnel after being stirred. One day later, the oil and ethanol were separated. The two liquids were independently stored in a beaker and weighed in volume. Repeated procedures with another solvent. Analysis was carried out on the extracting oil ratio of solvent as well as impurities. Viscosity, flash point, density and colorimetric analysis of recovered oil was conducted using different techniques. In the chemical laboratory, the flash point study of the extracted oil was performed. The lowest temperature at which it can vaporize and form an ignitable substance in the air is the flash point of a reactive substance. Measuring a flash point requires a source of ignition. At the flash point, when the ignition source is removed, the vapor can cease to fire. In open cup devices, the sample is contained in an open cup that is heated and a flame is carried over the surface at intervals. In fact, the measured flash point varies with the height of the flame above the liquid surface, and the measured flash point temperature would coincide with the fire point at an appropriate height. The final process was achieved by quick 
distillation of used motor oil using liquid solvents to extract solid content, water, and gasoline and light materials. For the extraction of base oil from used car oil, three solvents were used, namely n-Butanol, 1-Propanol and Ethanol. The magnetic stirrer is a laboratory instrument composed of either a revolving electromagnet or a fixed rotating magnetic field. By agitating or mixing with magnetic bead, this system is used to spin the liquid very rapidly and heating is achieved via a heating pad. In the magnetic stirrer, $50 \mathrm{ml}$ of used engine oil and $50 \mathrm{ml}$ of solvent and other ratios $(50 \mathrm{ml}$ of used oil and $100 \mathrm{ml}$ of solvent) and (100 ml of used oil and $50 \mathrm{ml}$ of solvent) are stirring for 10 minutes at $500 \mathrm{RPM}$ at a temperature set at $60 \mathrm{C}$ and the procedure is repeated at various ratios for each solvent. Using $50 \mathrm{ml}$ of used fuel oil and $50 \mathrm{ml}$ of solvent n-Butanol, quick distillation was accomplished. The mixture was put under $118{ }^{\circ} \mathrm{C}$ in a boiling flask. Product extraction, though, was much lower since the oil was not condensed within the distillate. It was distilled into the flask itself and collected. Although the recovery of oil was carried out in simple distillation for oil recovery. In the distilling flask, 50 $\mathrm{ml}$ of used oil and $50 \mathrm{ml}$ of solvent were removed and put inside the heating mantle. Repeated the procedure with the different volume and time taken for oil recovery for each solvent. To verify which process is easier to recover more oil in less time, a comparison of the rate of oil recovery between filtration and basic distillation was conducted. In both approaches, study of the properties of recovered engine oil was conducted by testing physical properties such as hue, flash point, density, etc. Until beginning the method of recycling of used oil, this experiment is based on the knowledge and calculation of certain properties.

2.3 Separation by Solvents ( $n$-Butanol, 1-Propanol and Ethanol). Using solvents, this process removes impurities and carbon particles from pure oil (n-Butanol, 1-Propanol and Ethanol). The instruments to be used in the experiment are: 100 $\mathrm{ml}$ volume measurement cylinder, $500 \mathrm{ml}$ volume beaker, Magnetic stirrer, $100 \mathrm{ml}$ ring clamp \& ring stand (n-Butanol, 1Propanol, Ethanol). Separation process is shown in Figure 2.2.

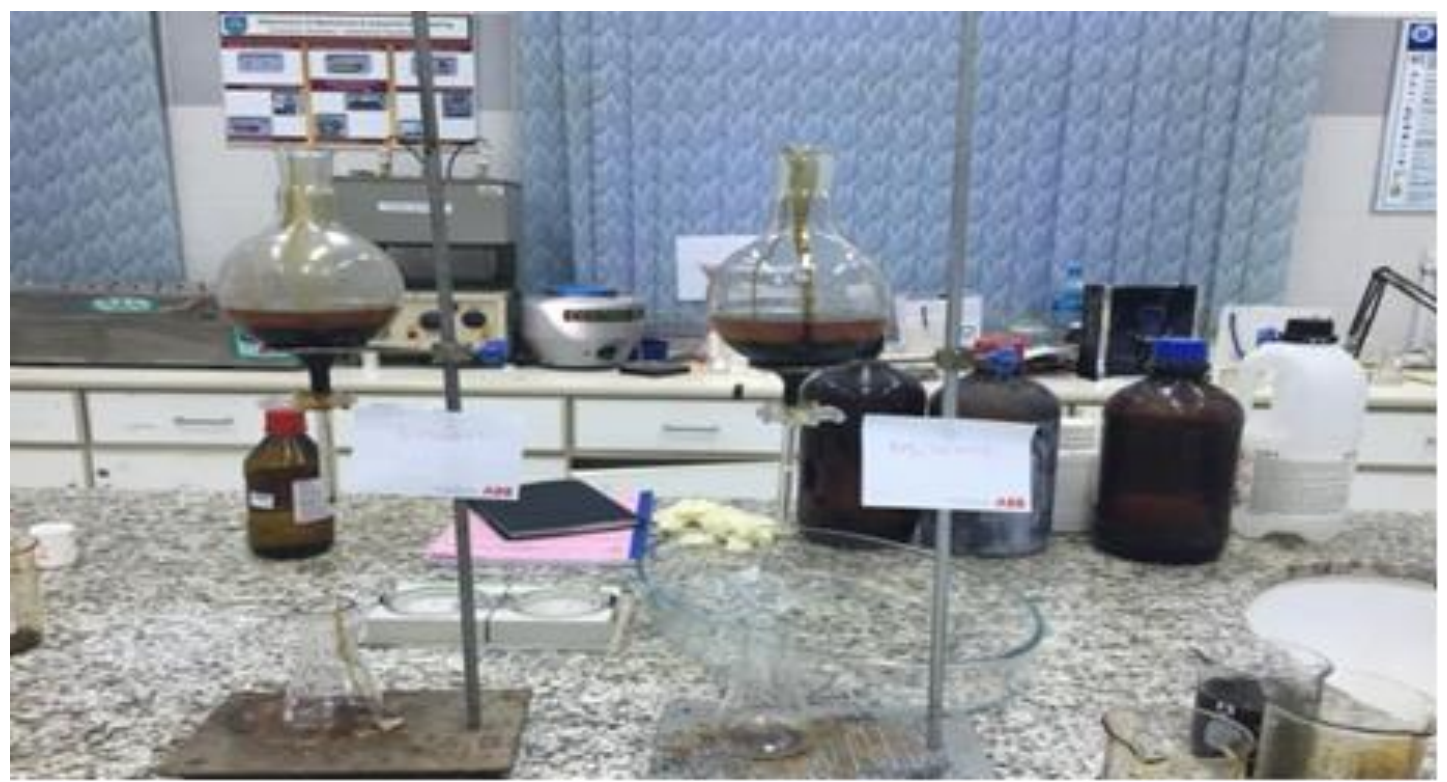

Figure 2.2: Separation funnels with used oil and Solvent

Three $500 \mathrm{ml}$ volume beakers are added in the beaker with $100 \mathrm{ml}$ motor oil and $100 \mathrm{ml} \mathrm{n}$-butanol solvent. At $60^{\circ} \mathrm{C}$, a magnetic stirrer and hot plate combine the solution. The mixture is then injected into the isolation funnel and separated for 24 hours. Repeat with 1-propanol and ethanol solvent. It then measures extracted oil length, viscosity, density, flash point. 
2.4 Recovery of solvent using simple Distillation. Solvent extraction is an important hydrocarbon separation, purification and recovery process. This stage typically includes purifying used oil by removing suspended solids. However, oil also contains partially oxidized soluble compounds that must be isolated by a simple distillery. Fast distillation to end oil solvent. The instruments to be used in the experiment are: $100 \mathrm{ml}$ measuring cylinder length, $200 \mathrm{ml}$ volume beaker, 200 $\mathrm{ml}$ used oil volume, $200 \mathrm{ml} \mathrm{n}$-butanol, 1-propanol and ethanol, mixture distillation flask, heating mantle and condenser. Figure 2.3 indicates the speed of distillation.

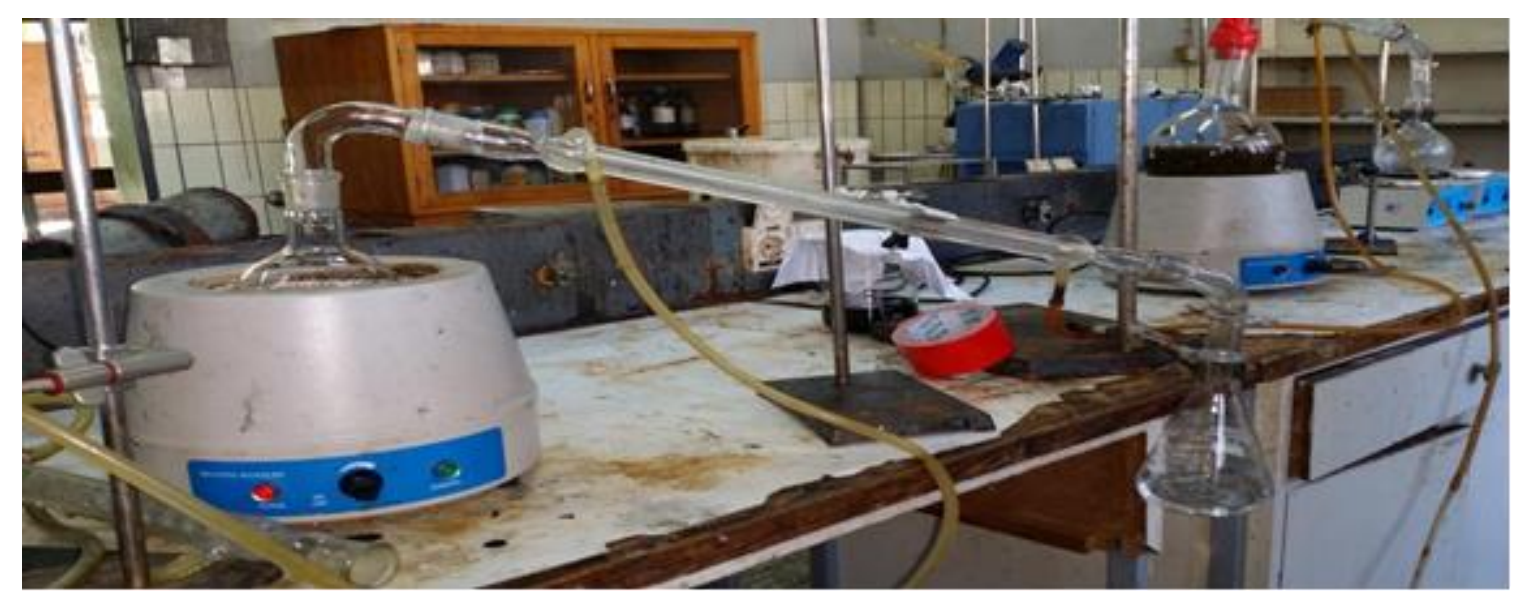

Figure 2.3: Simple Distillation Process

In a beaker $50 \mathrm{ml}$ of filtration fluid is blended with $50 \mathrm{ml}$ solvent (n-butanol). Using a magnetic stirrer with a 5minute hot plate mixes the spent oil and solvent $n$-butanol. Then pour the mixture into the distilling bottle for easy distillation. Pressure the mixture to the boiling point (n-butanol), which is $118^{\circ} \mathrm{C}$.solvent, then evaporate and condense. Measure solvent length, solvent depletion, ash content, oil residue, color and flash point. Repeat with another solvent, but for particular oil to solvent ratios (1-propanol, ethanol.

\section{RESULT AND DISCUSSIONS}

The absolute gravity of used oil at $15^{\circ} \mathrm{C}(0.869)$ exceeds unused oil $(0.8622)$. Used oil density $(0.868 \mathrm{~g} / \mathrm{cm} 3)$ is higher than unused oil $(0.861 \mathrm{~g} / \mathrm{cm} 3)$ at a temperature of $15^{\circ} \mathrm{C}$. The kinematic viscosity at $40^{\circ} \mathrm{C}$ and $100^{\circ} \mathrm{C}$ is $81.1 \mathrm{cSt}$ and $12.2 \mathrm{cSt}$ respectively. This volume exceeds surplus oil at the same temperature at $70.2 \mathrm{cSt}$ and $11.6 \mathrm{cSt}$ respectively. The unused oil viscosity index (159) exceeds used oil (146.838). Unused oil flash point $\left(210^{\circ} \mathrm{C}\right)$ is more than used oil $\left(200^{\circ} \mathrm{C}\right)$. More sulphated ash content in the oil used $(5.25 \% \mathrm{wt})$ than the unused oil (2.93 percent wt.). The pour point of used oil $\left(-30{ }^{\circ} \mathrm{C}\right)$ is more than unused oil $\left(-24^{\circ} \mathrm{C}\right)$. The fire point of used oil $\left(230^{\circ} \mathrm{C}\right)$ is more than unused oil $\left(220^{\circ} \mathrm{C}\right)$. The average base number (TBN) in the unused oil is higher than the used oil $(0.69 \mathrm{mg} \mathrm{KOH} / \mathrm{g})$. The oil used is darker (8) than unused oil. The carbon residue is more of the oil used $(1.00 \% \mathrm{wt})$ than unused oil $(0.680$ percent wt). Finally, water content of the oil used $(240 \mathrm{mg} / \mathrm{kg})$ exceeds that of unused oil $(210 \mathrm{mg} / \mathrm{kg})$.

Figure 3.1 displays properties of used and unused engine oil at varying temperatures $\left(40^{\circ} \mathrm{C}, 100^{\circ} \mathrm{C}\right)$ before solvent extraction. Kinematic viscosity (v) was observed using temperature-decreased Saybolt Viscometer. Mass and density (p) are also high at cold, low temperatures. The specific gravity of used engine oil (0.855) and unused engine oil (0.850) at different temperatures remains the same and the flash point of used engine oil (180) and unused engine oil (210) remains the same at different temperatures. 


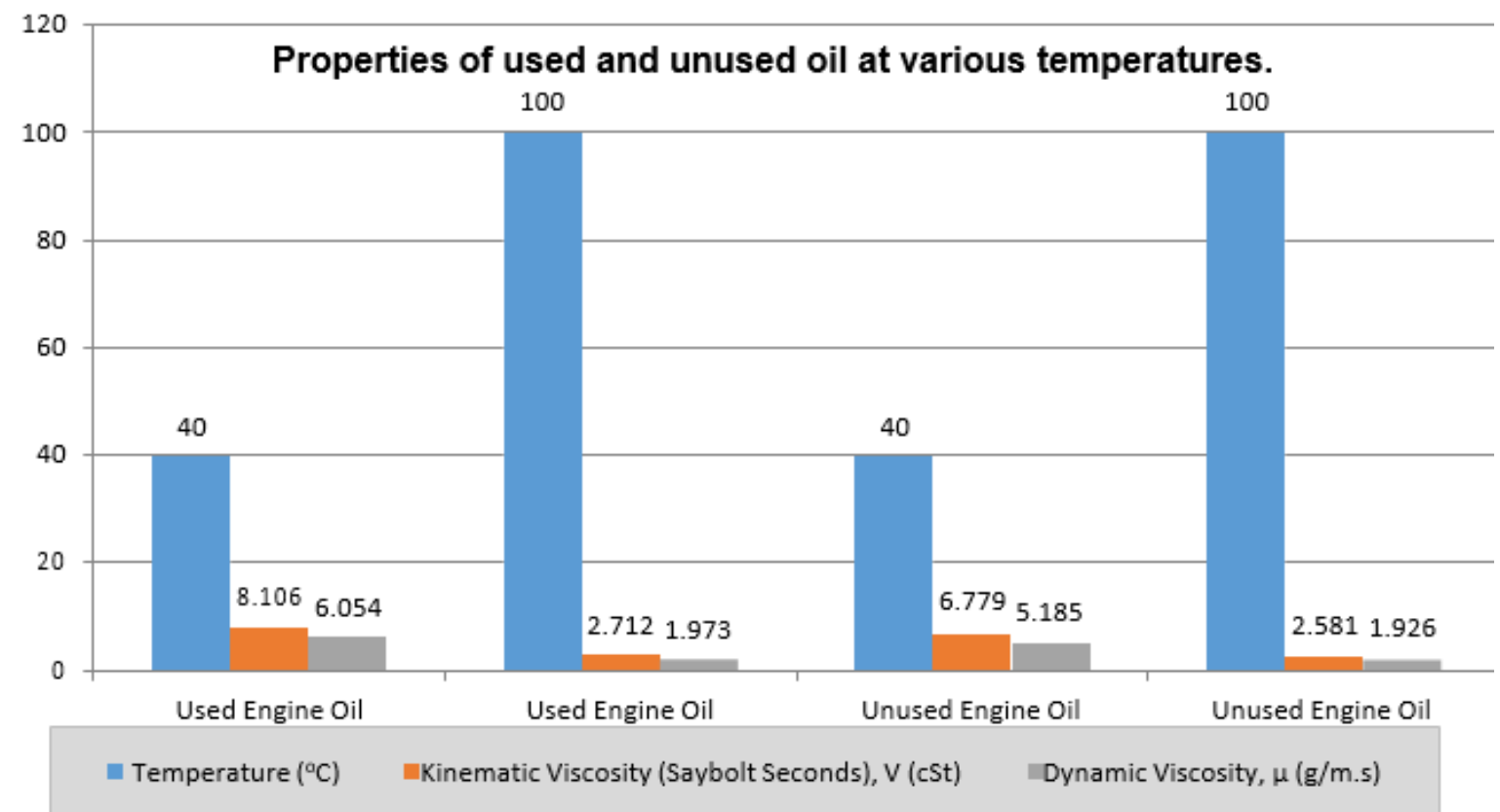

Figure 3.1: Comparative Analysis of used and unused engine oil at Various Temperatures.

Figure 3.2 reveals that the ash content reduces as time increases. As time increases, the loss of oil decreases. When the time rises, oil extract increases.

\section{Ash content wt..$\%$}

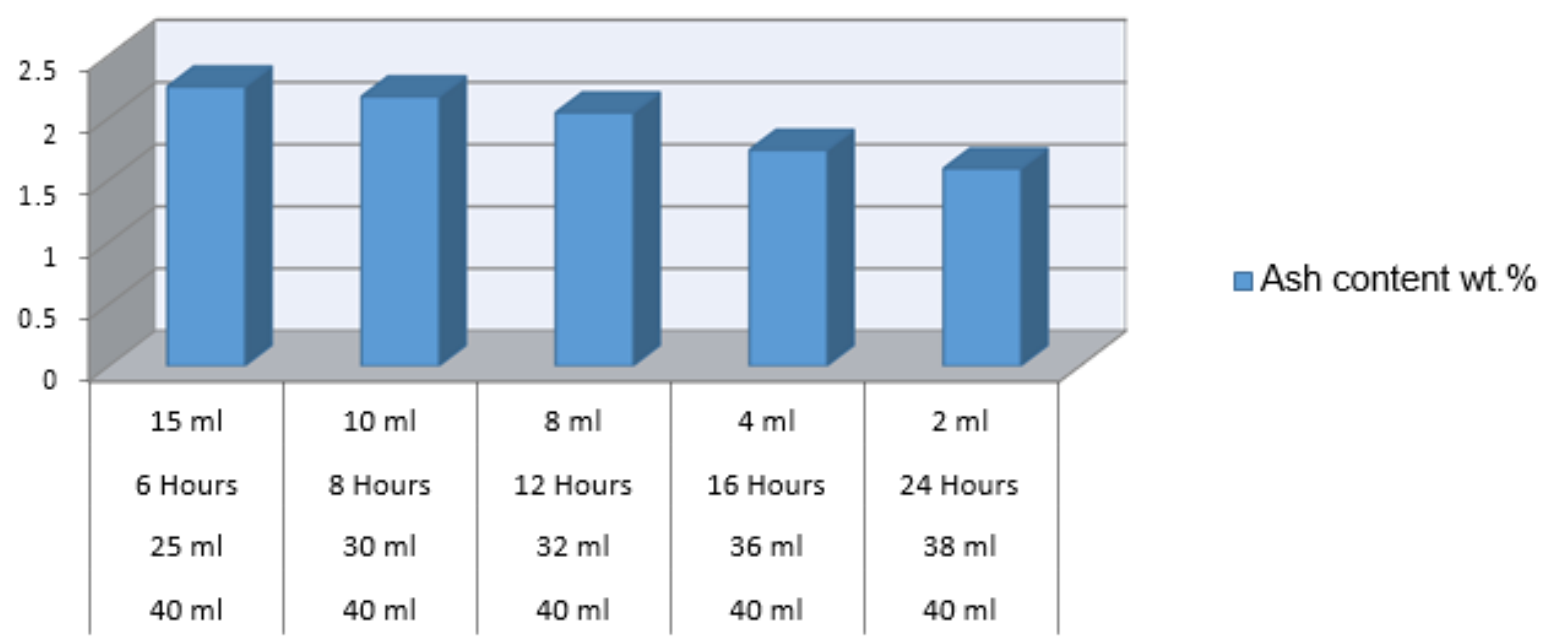

Figure 3.2: Filtration of used Engine Oil by using Whatman Filter Paper.

Figure 3.3 indicates decreased ash content as time rises at the same flow rate. As time increases at the same flow rate, the loss of oil reduces. The extraction of oil increases as the time increases at the same flow rate. With drops in pressure, the flow rate increases. If the friction increases, the flow rate decreases. In contrast with Whatman filter paper, the ISCO syringe pumps are the better and quicker form of filtration. In contrast to Whatman filter pad, more oil is removed relative to the ISCO syringe pump. So the filtration of the ISCO syringe pump is better. 


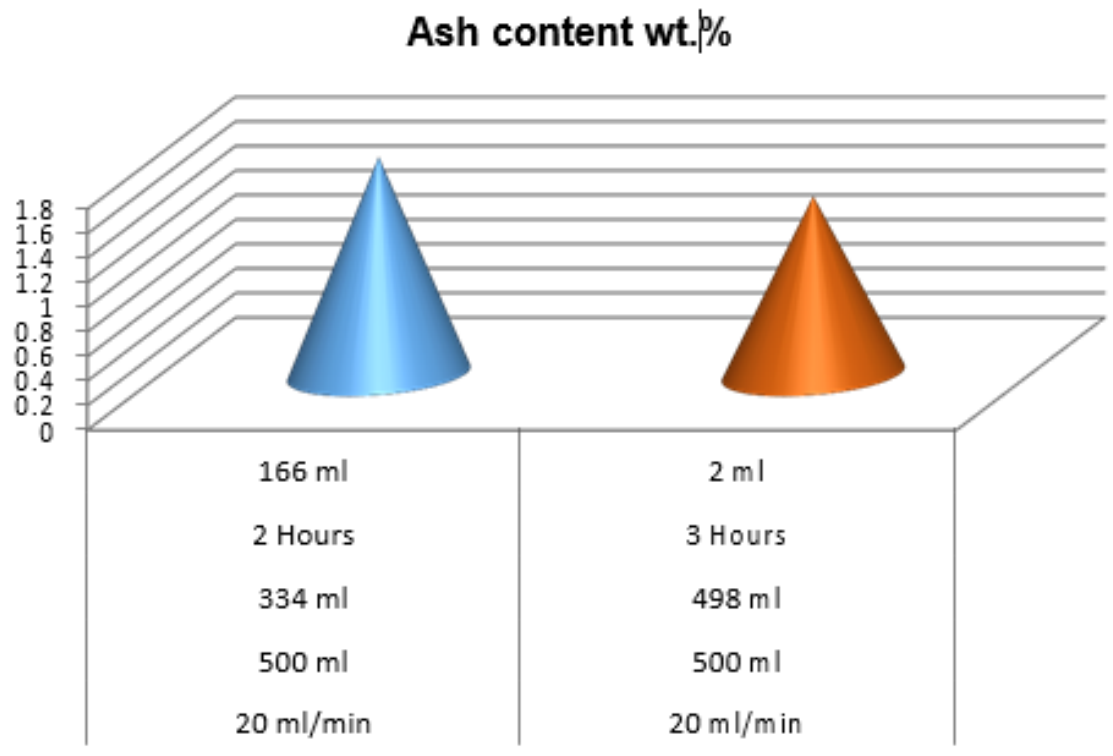

Figure 3.3: Filtration of Used engine oil by using ISCO Syringe Pump.

Figure 3.4 reveals more oil is extracted using n-butanol solution. Further solvent extraction was achieved using ethanol solvent. Oil loss is greater because solvent is ethanol. Ash content is observed for extraction using 1-Propanol as solvent. For ethanol oil separation, the flashpoint was higher.

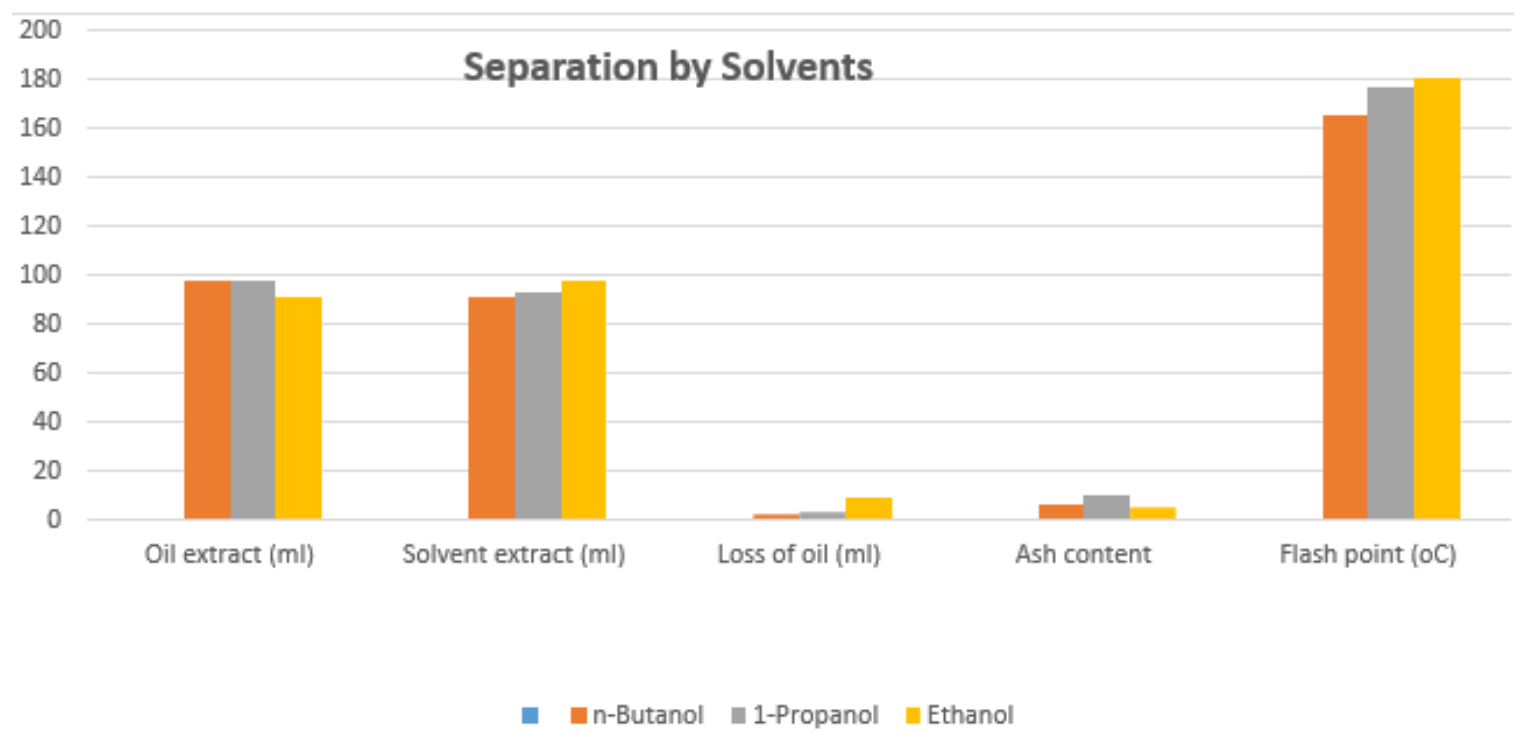

Figure 3.4: Comparative analysis of separation of oil by three solvent (n-Butanol,1-Propanol, Ethanol).

\section{CONCLUSIONS}

The engine oil used is a high pollutant requiring joint public and social regulation and transparency. Since the use of engine oil causes environmental damage and leads to groundwater and soil contamination, it is often difficult and costly to get rid of it, particularly if handled correctly. Recycling these toxins is very effective in reducing engine oil prices. It also has a significant positive environmental and social impact. The oil lubrication base used was the solution to this concern. The safest approaches are recycling using non-toxic and cost-effective materials. 
This reserach article began with choosing the engine oil used to determine the volume of virgin oil that deteriorates in it, selecting the equipment and materials used for testing, and selecting solvent types such as n-butanol, 1propanol and ethanol. In order to select the properties of the engine oil used, specific gravity, density, viscosity (index \& kinematic), flash point, fire point, pour point, sulphate ash content, total base number (TBN), color, carbon residue and water content of the recovered engine oil were then analysed.

This research was a study of the various isolation forms used to recover used engine oils. Recycled engine oil properties were measured and compared to the initial oil. Although the extract quantity was high, solvent extraction was found to be more effective among various methods used to obtain the oil used. Using ethanol solvent oil treatment produced extract in easy distillation compared to n-butanol and 1-propanol solvent. Thus, based on current research, solvent selection as well as method for recovery of used oil was developed.

\section{REFERENCES}

1. Boyde, S., 2002. Green lubricants: Environmental benefits and impacts of lubrication. Journal of royal society of chemistry, Green chemistry. 4(4). p. 293-307.

2. Wong, P.K., \& Wang, J., 2001. The Accumulation of Polycyclic Aromatic Hydrocarbons in Lubricating Oil over time: A comparison of Supercritical Fluid and Liquid-Liquid Extraction Methods. Environmental Pollution. 122. p. 407-415.

3. Chung, M.K., Hu, R., Cheung, K.C. \& Wong, M.H., 2007. Pollutants in Hong Kong soils Polycyclics Aromatic Hydrocarbons. Chemosphere. 6 (7). p. 464-473.

4. Kanokkantapong, V., Kiatkittipong, W., Panyapinyopol, L., Wongsuchoto,P. \& Pavasant, M., 2009. Used lubricating oil management options based on life cycle thinking resources. Conservation and recycling. 5 (3). p. 294-299.

5. Dang, G.S., 2006. Rerefining of Used Oils: A review of Commercial Process.Journal of Wiley Inter Science. 3 (4). p. $445-457$.

6. Durani, H.A., Panhwar, M.I. \& Kazi, R.A., 2010. Re-refining of waste lubricating oil by Solvent Extravtion. Mehran University Research Journal of Engineering and Technology. 30 (2). p. 237-246.

7. Rahman, M.M., Siddiquee, T.A., Samdani, S. \& Kabir, K.B., 2008. Effect Operating Variables on Regeneration of Base Oil from Waste Oil by Conventional Acid-Clay Method. Chemical Engineering Research Bulleting. 12 (4). p. 24-27.

8. Hani, F.B. \& Al-Wedyan, H., 2011. Regeneration of base-oil from waste-oil under different conditions and variable. African Journal of Biotechnology Antje Hansmeier. 9 (4). p. 86-90.

9. Shakirullah, M., Ahmad, I., Saheed, M., Khan, M. A., Habib-Ur-Rehman, A., Ishaq, M. \& Shah, A. A., 2006. Environmentally Friendly Recovery and Characterization of Oil from Used Engine Lubricants. Journal of the Chinese Chemical Society. 5 (3). p. 335-342.

10. Katiyar, V. \& Hussain, S., 2010. Recycling of Used Lubricating Oil Using 1-Butanol. International Journal of Chemical Science. 8(3). p. 1999-2012. 